\title{
Alteration, mass analysis, and magmatic compositions of the Sentinel Bluffs Member, Columbia River flood basalt province
}

\author{
Michael G. Sawlan \\ U.S. Geological Survey, 345 Middlefield Road, Menlo Park, CA 94025 MS-973
}

\section{SUPPLEMENTAL FILE 1}

\section{Previously Published Analyses of Sentinel Bluffs Member Samples}

The primary source of the earlier SB data is the compilation of Reidel and Valenta (2000), which includes 777 unique analyses (not including replicate analyses). In addition, thirty previously unreported analyses from Reidel (2005) and a total of seven analyses from Derkey et al. (1999, 2004) were also considered. These analyses were performed at the GeoAnalytical Lab, WSU, prior to a change in instrumentation (and in some analytical procedures) in mid-2004. Supplemental File 3 describes differences in the accuracy and precision of these analyses compared to the more recent analyses. Among the analyses in Reidel and Valenta (2000), most are from samples collected for the Basalt Waste Isolation Project (BWIP). Other data sources referenced in Reidel and Valenta (2000) (see their Appendix A) include geologic mapping studies, theses, and previously unpublished data from several contributors.

\section{Analyses Excluded from Consideration}

The Reidel and Valenta (2000) compilation of SB analyses was produced as a "preliminary" report and, upon inspection of these earlier SB analyses, it became apparent that some analyses were not of samples from SB lavas. A small number of analyses with low-MgO were readily identified as belonging to lavas of older Grande Ronde Basalt (GRB) members (e.g., Winter Water and Ortley) that underlie SB lavas at many locations. These identifications were confirmed from BWIP reports that show sample positions in stratigraphic columns for several localities, as well as from comparisons to analyses of GRB lavas (author's unpubl. data) in the continuously sampled sections (see Fig. 1, main report). In addition, a number of samples 
have $\mathrm{Cr}$ abundances much greater than those of the SB samples analyzed for this study. Except for the few samples noted above, information on stratigraphic position for the majority of samples in the previously published SB dataset is unavailable. The relative position of borehole samples is given by depth values that were included as part of their sample numbers, but the positions of samples relative to flow contacts are unknown.

In the absence of stratigraphic constraints, which could be used to identify non-SB analyses within the compilation, chemical criteria were used to filter out non-SB analyses. The objective was to exclude non-SB samples while avoiding exclusion of those SB samples with compositions modified by alteration. Threshold values were established based on analyzed abundances of this study. To facilitate comparisons between the pre- and post-2004 analyses, empirical adjustments to previously reported values (normalized to $100 \%$ anhydrous) were made to several elements $\left(\mathrm{Cr}^{*}=\mathrm{Cr}-11 ; \mathrm{TiO}_{2}{ }^{*}=\mathrm{TiO}_{2} \cdot 1.025 ; \mathrm{Zr}^{*}=\mathrm{Zr} \cdot 1.08\right)$. Threshold values applied to the older SB dataset are listed below. Adjusted values are indicated by an asterisk.

- $10<\mathrm{Cr}^{*}<70$

- $\quad 6.6<\mathrm{Al}_{2} \mathrm{O}_{3} / \mathrm{TiO}_{2} *<8.6$ (all samples)

- $\mathrm{Al}_{2} \mathrm{O}_{3} / \mathrm{TiO}_{2} *>7.4$ (Series V samples)

- $\mathrm{Sc} / \mathrm{Cr}^{*}>1.7$ and $\mathrm{Ti}^{*} / \mathrm{Zr}^{*}<68.5$

- $\mathrm{MgO} \leq 5.5$

- $\quad \mathrm{MgO}<4.1$ and $\mathrm{Cr}^{*}>15$

The 70-ppm Cr* maximum threshold was selected based on several considerations. Given that the maximum $\mathrm{Cr}$ abundance observed in this study is $\sim 48 \mathrm{ppm}$, the 70-ppm threshold allowed for ample concentration of $\mathrm{Cr}$ in mass-depleted rock as well as for larger analytical uncertainties in the older dataset. In addition, the 70-ppm threshold is within a gap in $\mathrm{Cr}$ abundances in this older dataset. To allow for large analytical uncertainty at low $\mathrm{Cr}$ abundances, the $\mathrm{Cr}^{*}$ minimum threshold was chosen to be $5 \mathrm{ppm}$ lower than the lowest $\mathrm{Cr}$ abundance of SB lavas observed in this study. Analyses with high $\mathrm{Cr}^{*}$ and (or) $\mathrm{MgO}$ likely correspond to lavas of $\mathrm{N}_{2}$ GRB members having high to very high MgO, such as the Slack Canyon and Indian Ridge Members of Reidel and Tolan (2013). 
Ratios of immobile elements (i.e. $\mathrm{Al}_{2} \mathrm{O}_{3} / \mathrm{TiO}_{2}$, Sc/Cr, Ti/Zr) were used in several criteria because these ratios are independent of alteration effects. Samples having both high Sc/Cr and low Ti/Zr ratios were not observed in SB lavas analyzed for the present study (see Fig. 3, main report), and the combined thresholds of $\mathrm{Sc} / \mathrm{Cr}$ and $\mathrm{Ti} / \mathrm{Zr}$ ratios excluded several samples with anomalous compositions.

The MgO maximum threshold of 5.5 wt. \% excluded analyses with anomalously high MgO values compared to the maximum MgO of SB lavas analyzed in this study ( 5.2 wt. \%; see Fig. 12, main report), while allowing for a possible intra-laboratory bias of the older data to higher MgO. The criterion based on combined $\mathrm{Cr}^{*}$ and $\mathrm{MgO}$ thresholds was applied to exclude samples of older GRB members (e.g., Winter Water and Ortley) having both low Cr and low MgO. The Cr minimum threshold corresponds to the lowest Cr abundances observed in SB lavas of this study. Although altered SB lavas can have low MgO abundances, the Cr abundances of such samples would increase as a function of the reciprocal of the remaining mass fraction.

The main criteria by which samples from the earlier dataset were excluded from consideration were high $\mathrm{Cr}^{*}(\mathrm{n}=22)$, high $\mathrm{MgO}(\mathrm{n}=11)$, and combined high Sc/Cr* and low $\mathrm{Ti}^{*} / \mathrm{Zr}^{*}(\mathrm{n}=13)$. Less than 10 samples were excluded by each of the other criteria. One sample with low anomalously low $\mathrm{TiO}_{2}(<1.57)$ was discarded, as was a sample with MgO within the range of SB lavas but with anomalously high $\mathrm{TiO}_{2}$. Three borehole samples excluded by the above criteria are bracketed vertically by samples that are undoubtedly of SB lavas. It appears that the analyses of these samples are errant, at least with respect to abundances of those elements applied in the threshold values. Among the samples excluded by these criteria, a number of them did not meet two or more criteria. Although a Ti/Zr threshold was not used as a criterion, samples with anomalously high and low Ti/Zr were excluded by the criteria used.

In addition to the chemical criteria described above, a small number of analyses were omitted based on other criteria. Analyses of dikes correlated to SB lavas (Reidel, 2005) were excluded. Several analyses of lavas from the vicinity of Spokane, Washington, identified by Reidel (2005) as the California Creek and Airway Heights compositional types, were excluded because of their uncertain stratigraphic position relative to other SB lavas. These lavas underlie a flow which is correlative with SB Group 10 of this study and which was designated as the Spokane Falls compositional type by Reidel (2005). Their lower stratigraphic constraint is only that they overlie reversed polarity GRB lavas of the $\mathrm{R}_{2}$ magnetozone. Analyses of samples 
having relatively high $\mathrm{TiO}_{2}$ and $\mathrm{P}_{2} \mathrm{O}_{5}$ abundances from other locations, however, were included in the present analysis.

As refined, the earlier SB dataset comprised 748 analyses, which were considered in the analysis of TiO2-MgO and $\mathrm{Al}_{2} \mathrm{O}_{3}-\mathrm{TiO}_{2}$ variations in the main report (see Figures 2 and 13, main report).

\section{MI'100 Baseline Determinations}

In calculating $M I^{100}$ baselines and sample mass indexes from $\mathrm{Al}_{2} \mathrm{O}_{3}$ and $\mathrm{TiO}_{2}$ data of the older dataset (see Fig. 13, main report), the differentiation of samples between an aggregated Series I-IV and Series V was made primarily on differences in Ti/Zr ratios. Samples having high $\mathrm{Ti} / \mathrm{Zr}$ were assigned to Series I-IV, and those having low Ti/Zr were assigned to Series V (see Fig. 3). For borehole samples where relative vertical position is known, relative differences in $\mathrm{Ti} / \mathrm{Zr}$ ratios were also taken into account in assigning samples to Series V and Series I-IV. It is possible that a small number of samples having Ti/Zr intermediate between Series IV and V (see Fig. 5A, main report) and having $\mathrm{Al}_{2} \mathrm{O}_{3} / \mathrm{TiO}_{2}$ within the range where Series IV and $\mathrm{V}$ $\mathrm{Al}_{2} \mathrm{O}_{3} / \mathrm{TiO}_{2}$ overlap (see Fig. 12, main report) might have been misidentified. This mainly applies to samples from surface exposures for which stratigraphic information is lacking. Because the $M I^{100}$ lines differ only slightly between Series V and the combined Series I-IV, potentially incorrect assignments would be inconsequential. For Series V samples, the sample mass index calculated from either line is equivalent for those samples with lower $\mathrm{Al}_{2} \mathrm{O}_{3} / \mathrm{TiO}_{2}$ of this Series and differs by less than several tenths of one $M I$ unit for those samples having the highest $\mathrm{Al}_{2} \mathrm{O}_{3} / \mathrm{TiO}_{2}$ ratios among Series $\mathrm{V}$ samples

The $\mathrm{Al}_{2} \mathrm{O}_{3}-\mathrm{TiO}_{2}$ distribution of previously published SB analyses differs from the $\mathrm{Al}_{2} \mathrm{O}_{3^{-}}$ $\mathrm{TiO}_{2}$ distribution observed in this study in that a small number of samples from the earlier dataset plot below the main fields (see Fig. 13, main report). These samples are interpreted as having experienced mass increases, presumably by precipitation of secondary minerals. Such samples therefore were disregarded in determining the $M I^{100}$ lines. In defining $\mathrm{Al}_{2} \mathrm{O}_{3}-\mathrm{TiO}_{2}$ baselines using an iterative calculation method (see Supplemental File 4, explained in Supplemental File 3), the initial (user-defined) line was positioned at the base of the main sample population rather than along the few samples having the lowest $\mathrm{Al}_{2} \mathrm{O}_{3}$ and $\mathrm{TiO}_{2}$ abundances. 


\section{Identification of Borehole and Surface Samples}

Samples from multiple boreholes drilled during BWIP were identified by sample-number suffixes indicating depth, specified to 1 foot for core samples, and to 5 or 10 feet for rotary drilling chips. Most borehole samples are from depths between 537 and $1122 \mathrm{~m}$; the most shallow depth of subsurface SB samples in the older dataset is $\sim 120 \mathrm{~m}$. All samples identified as subsurface from their sample numbers are undoubtedly from boreholes, but other samples identified as surface samples might actually have come from boreholes (if numbered arbitrarily). For instance, subsets of samples from two locations, each having sample numbers lacking depth reference and with all samples having identical locations, are located within areas of alluvial cover based on comparisons between their locations, given as Public Land Survey System descriptions (PLSS; i.e. Township-Range-Section-Quarter-Quarter Part)) and aerial imagery (National Agriculture Imagery Program (NAIP), 2-m resolution or better). Although this suggests that the samples from these two locations are from boreholes, errors in the PLSS descriptions cannot be ruled out. Thus, in the comparison of borehole and surface samples (see Fig. 13, main report), these samples were assigned the symbols given to surface samples.

\section{References Cited}

Derkey, R.E., Hamilton, M.M., and Stradling, D.F., 1999, Preliminary geologic maps of the Spokane NE and SE 7.5-minute quadrangles, Spokane County, Washington: Washington Division of Geology and Earth Sciences Open File Report 2004-1, Washington Department of Natural Resources, Olympia.

Derkey, R.E., Hamilton, M.M., and Stradling, D.F., 2004, Geologic map of the Airway Heights 7.5-minute quadrangle, Spokane County, Washington: Washington Division of Geology and Earth Sciences Open File Report 2004-1, Washington Department of Natural Resources, Olympia.

Reidel, S.P., 2005, A lava flow without a source: The Cohassett flow and its compositional components, Sentinel Bluffs Member, Columbia River Basalt Group: Journal of Geology, v. 113, p. 1-21, doi: 10.1086/425966.

Reidel, S.P., and Valenta, M.M., 2000, Preliminary chemistry, petrology, and paleomagnetism data for the Sentinel Bluffs Member, Columbia River Basalt Group: Battelle Pacific Northwest Laboratories Report PNWD-3063, 279 pp., Richland. 